\title{
Characterization and Antibacterial Activity of Oil-In-Water Nano-Emulsion Formulation Against Candidatus Liberibacter asiaticus
}

C. Y. Yang, State Key Lab for Conversation and Utilization Subtropical Aro-Biological Resources, Guangxi University, Nanning, Guangxi, 530005, China, IRREC-IFAS, University of Florida, Fort Pierce, FL 34945, and Fujian Agriculture and Forestry University, Fuzhou, 350002, China; C. A. Powell, IRREC-IFAS, University of Florida, Fort Pierce, FL 34945; Y. P. Duan, USHRL, USDA-ARS, Fort Pierce, FL 34945; and M. Q. Zhang, State Key Lab for Conversation and Utilization Subtropical Aro-Biological Resources, Guangxi University, Nanning, Guangxi, 530005, China, IRREC-IFAS, University of Florida, Fort Pierce, FL 34945, and USHRL, USDA-ARS, Fort Pierce, FL 34945

\begin{abstract}
Yang, C. Y., Powell, C. A., Duan, Y. P., and Zhang, M. Q. 2016. Characterization and antibacterial activity of oil-in-water nano-emulsion formulation against Candidatus Liberibacter asiaticus. Plant Dis. 100:2448-2454.

Nano-emulsion is a promising delivery system for increasing pesticide use and enhancing the therapeutic efficiency against pathogens. The pathogen Candidatus Liberibacter asiaticus (Las) that causes destructive citrus huanglongbing (HLB) resides in citrus phloem, which makes it difficult to treat with chemicals. Based on various physiochemical characteristics of oils, surfactants, and organic solvents, an oil-in-water $(\mathrm{O} / \mathrm{W})$ nano-emulsion formulation was developed and optimized to combat citrus HLB. The nano-emulsion was formulated through a spontaneous emulsification method for efficient delivery of ampicillin into the citrus phloem using bark application. The nano-emulsion that was prepared from Cremophor EL (viscous oil), acetone (water miscibility organic solvent), and Span 80/Tween 80 (surfactant) formed a small droplet size $(17.33 \pm 0.52 \mathrm{~nm})$ and exhibited an improved absorption rate. Peak

concentration was detected at 2 days posttreatment and the maximum concentration $\left(\mathrm{C}_{\max }\right)$ and relative bioavailability (RBA) of ampicillin in HLB-affected citrus were $71.86 \pm 35.38 \mathrm{ng} / \mathrm{g}$ and $267.25 \% \pm 44.1 \%$, respectively. The peak concentration of Amp appeared at 6 days posttreatment in the citrus trees that were treated with Amp alone and their $\mathrm{C}_{\max }$ and RBA were $56.44 \pm 32.59 \mathrm{ng} / \mathrm{g}$ and $100 \%$, respectively. The same nano-emulsion was used to deliver five different antimicrobials to control citrus HLB through bark application. We found that the droplet size of the antimicrobials in the nano-emulsion was significantly reduced and the nano-emulsion also enhanced the therapeutic efficiency of validoxylamine A alone and in combination with actidione as well as sulfadimoethoxine sodium against Las. Therefore, this study provides an efficient bark application nano-emulsion formulation for citrus HLB control.
\end{abstract}

Citrus huanglongbing (HLB) is one of the most serious diseases known in citrus production and has caused severe economic losses in citrus production in Asia and Africa (da Graça and Korsten 2004). Since HLB was first observed in Florida in 2005, citrus acreage and production have declined from 750,000 acres and 170 million boxes to 520,000 acres and less than 80 million boxes in 2015-2016, respectively (Neupane et al. 2016). By 2020, HLB is predicted to cause a 23\% crop loss in Florida (Hodges and Spreen 2012; Spreen et al. 2006). HLB is associated with phloem-limited bacteria, Candidatus Liberibacter sp., which can be transmitted by psyllids, Diaphorina citri, or Trioza erytreae (Bové 2006; Bové and Ayres 2007; Gottwald 2010; Jagoueix et al. 1994; Texeira et al. 2005). Control of HLB in the field is urgently needed. Although psyllid management and inoculum removal reduce the rate of HLB infection in large farms in Brazil, the majority of citrus trees in small and medium-size groves often do not benefit from such integrated management practices (Spann et al. 2014). In addition, there are no known citrus species or cultivars that are resistant to HLB (Lopes and Frare 2008; Nariani et al. 1973). Today, with the unprecedented citrus HLB epidemics in Florida and other citrus-growing regions throughout the world, there is an immediate need for development of novel methods such as chemotherapy, including the use of antibiotics. In a previous study we screened several compounds, such as ampicillin, carbenicillin, and penicillin, for their antimicrobial activity against HLB

\section{Corresponding author: Muqing Zhang; E-mail: mqzhang@ufl.edu}

*The $\boldsymbol{e}$-Xtra logo stands for "electronic extra" and indicates that one supplementary table and one supplementary figure are available online.

Accepted for publication 5 July 2016.

http://dx.doi.org/10.1094/PDIS-05-16-0600-RE

(C) 2016 The American Phytopathological Society
(Zhang et al. 2010, 2011, 2012, 2014). We found that several factors can influence the activity of antimicrobial compounds against $C a$. L. asiaticus (Las), since active ingredients can be lost during the applications through drift, runoff, evaporation, photolysis, and hydrolysis as well as degradation by microorganisms (Kah and Hofmann 2014). The effective compounds failed to kill pathogens residing in plant phloem because only a small portion of the effective compounds actually entered the plant phloem (Chen et al. 2015; Hill et al. 2015). Therefore, application of these effective compounds for control of HLB should focus on improving the delivery method to reach the phloem.

Nanotechnology has been widely applied in agricultural practice today for enhancing the efficacy and reducing the amount of pesticides used (Kah and Hofmann 2014). Nano-emulsions were previously proposed as a possible vehicle for delivering effective compounds into citrus phloem, which could lead to significant environmental benefits. Nano-emulsions with a droplet size less than $200 \mathrm{~nm}$ are ideal nanomaterials for delivering active ingredients into plants (Solans et al. 2005). The small size of nano-emulsion droplets protects them from UV light and gives them inherent stability against creaming, sedimentation, flocculation, and coalescence (Solans et al. 2005). These emulsions are transparent and translucent with a bluish color and show high kinetic stability (Mason et al. 2006). Specially designed nanoparticles can also slow down the degradation of active ingredients or enhance their uptake into the leaves and other parts of the plant (Sekhon 2014). Nano-emulsions can also be formulated either by higher energy methods, such as high pressure homogenization and sonication, or lower energy methods, such as spontaneous emulsification, emulsion inversion point, phase inversion temperature, or composition (Anton et al. 2008; Date et al. 2010; Ostertag et al. 2012; Saberi et al. 2013). Spontaneous emulsification may have advantages over high energy approaches for certain applications because it i) is more effective for the production of very fine droplets; ii) requires lower equipment and energy costs; and iii) is simpler to implement. The physiochemical properties of nano-emulsions generated by spontaneous emulsification 
are dependent on many factors, including interfacial tension, interfacial and bulk rheology, surfactant solubility characteristics, surfactant phase behavior, surfactant structure, and system composition (oils, surfactant, and organic solvents) (Bouchemal et al. 2004; López-Montilla et al. 2002; Miller 1988). Although a spontaneous emulsification method to prepare nano-emulsions is widely applied in the pharmaceutical and food industries (Chang and McClements 2014; Gulotta et al. 2014; Vandamme and Anton 2010; Wang et al. 2009), it has not been used for agricultural applications to date (Song et al. 2009; Wang et al. 2007), particularly for controlling plant disease (Yang et al. 2015). As such, there is a poor understanding of the physiochemical basis of nano-emulsions and the major factors that affect the performance of an active ingredient in controlling plant diseases. We hypothesized that the application of an oil-in-water $(\mathrm{O} / \mathrm{W})$ nano-emulsion that was mixed through spontaneous emulsification for controlling citrus HLB might be more efficient through bark application than that of a water-in-oil (W/O) nano-emulsion administered through a foliar spray (Yang et al. 2015). Therefore, we have developed, optimized, and characterized a novel $\mathrm{O} / \mathrm{W}$ nano-emulsion delivery system using a spontaneous emulsification method that has a small droplet size and different physiochemical constituent characteristics (i.e., oil, surfactant, and organic solvent) to evaluate the pharmacokinetics of ampicillin delivered to citrus phloem through bark application. The optimized delivery system was used to deliver five antibiotics into citrus phloem and the therapeutic efficacy for controlling citrus HLB was evaluated.

\section{Materials and Methods}

Plant materials. Two-year-old healthy grapefruit (Citrus paradisi) seedlings were graft-inoculated with HLB-affected lemon $(C$. limon) scions and subsequently maintained in the greenhouse (temperature: $25 \pm 2{ }^{\circ} \mathrm{C}$ ) for further studies. After 6 months, HLBaffected citrus seedlings with typical HLB symptoms were then tested for the presence of $\mathrm{Ca}$. L. asiaticus using quantitative realtime PCR (qPCR) with $\mathrm{Ca}$. L. asiaticus-specific primers (HLBas, HLBr, and HLBp) (Li et al. 2006) and maintained in an insectproof greenhouse for further use.

Chemical regents. Solvents, including ethanol, acetone, 2-butanone, methyl acetate, and ethyl acetate, were obtained from Fisher Scientific (Waltham, MA). Oils were purchased from different suppliers, including soybean oil from Walmart (Fort Pierce, FL), Cremophor EL from Sigma-Aldrich (St. Louis, MO), as well as carvacrol and P-cymene from TCI (Klamath Falls, OR). Surfactants (Span 80, Span 85, Tween 20, and Tween 80) were supplied by Sigma-Aldrich. Two agricultural antibiotics (zhongshengmycin and validoxylamine A) were purchased from Fujian Kaili Bio-product Co. Ltd (Fuzhou, Fujian, China). Other antibiotics, such as actidione, ampicillin sodium, and sulfadimethoxine sodium, were obtained from Sigma-Aldrich.

Preparation and optimization of $\mathrm{O} / \mathrm{W}$ nano-emulsion. $\mathrm{O} / \mathrm{W}$ nano-emulsions were prepared using a spontaneous emulsification method as described by Bouchemal with some modifications (Bouchemal et al. 2004). Homogeneous organic solutions $\left(S_{1}\right)$ were composed of several different oils (100 mg of soybean oil, Cremophor EL, carvacrol, or P-cymene) and a lipophilic surfactant (14.44 mg of Span 80 or Span 85$)$ in an organic solvent $(1,000 \mathrm{mg}$ of acetone, ethanol, methyl acetate, 2-butanone, or ethyl acetate). The homogeneous aqueous phase $\left(\mathrm{S}_{2}\right)$ was made with water $(10 \mathrm{ml})$ and hydrophilic surfactant $(28.88 \mathrm{mg}$ of Tween 80 or Tween 20). The organic phase was stirred into the aqueous phase with magnetic stirring for $5 \mathrm{~min}$ to reach equilibrium. Finally, the organic solvent was removed by overnight evaporation in a fume hood.

All optimization experiments on oil, surfactant combinations, and organic solvents were performed at $25^{\circ} \mathrm{C}$. A split-split plot experimental design was used to evaluate the effect of oil, surfactant combinations, and organic solvents on droplet size and polydispersity index (PDI) of the nano-emulsion prepared using the spontaneous emulsification method. The entire plot consisted of oil types (soybean oil, Cremophor EL, carvacrol, or P-cymene), while surfactant combinations (Span 80/Tween 20, Span 80/Tween 80, Span 85/ Tween 20, or Span 85/Tween 80) and the organic solvents (acetone, ethanol, methyl acetate, 2-butanone, or ethyl acetate) were considered as the split and subsplit plots, respectively. Data were analyzed as a generalized linear mixed model using the SAS procedure GLIMMIX. The entire plot and subplot factors were treated as fixed effects and replication and its interaction with the whole plot factor as random effects. Differences among treatment levels were determined with the LINES option of the LSMEANS statement.

Physicochemical characterization of nano-emulsions. The physicochemical characteristics of nano-emulsions were analyzed immediately after preparation, including droplet size, polydispersity index (PDI), zeta potential (ZP), mobility (mob), conductivity (Cond), and $\mathrm{pH}$ value. The droplet size, $\mathrm{PDI}, \mathrm{ZP}$, mob, and Cond of emulsion was determined using Zetasizer Nano ZS (Malvern Instruments Ltd., Worcestershire, U.K.). The $\mathrm{pH}$ value was determined by $\mathrm{pH}$ meter (Seven Compact, China). All of the physicochemical characteristics were assayed in triplicate. The data were analyzed by Duncan's multiple range test using SAS software package.

Pharmacokinetic analysis of nano-formulation. Based on the droplet size, two nano-emulsions of Nano-Cre and Nano-Soy were prepared using Cremophor EL and soybean oil, respectively. All nano-emulsion components are presented in Table 1. Ampicillin was selected as the target compound for pharmacokinetic analysis using these nano-emulsions (Nano-Cre and Nano-Soy) in an in vitro bioassay. Nano-Cre and Nano-Soy were used to load ampicillin for the preparation of the nano-formulations, Nano-Cre-Amp and Nano-Soy-Amp. The prepared nano-emulsion was then dissolved into a 3,000 mg/liter ampicillin solution (water containing $0.1 \%$ Brij $35)$ at a ratio of $1: 50 \mathrm{~g} / \mathrm{ml}(\mathrm{w} / \mathrm{v})$ to create Nano-Cre-Amp and NanoSoy-Amp, respectively. The final ampicillin concentration of the nano-formulations (Nano-Cre-Amp and Nano-Soy-Amp) was 3,000 $\mathrm{mg} /$ liter. Ampicillin was also dissolved in water at a final concentration of 3,000 mg/liter as a negative control (Amp), whereas tap water containing $0.1 \%$ Brij 35 served as the blank control.

For the pharmacokinetic analysis, the Nano-Cre-Amp, Nano-SoyAmp, Amp solution (Amp), and Blank control were applied to HLBaffected citrus by bark application with six replicates each. A sharp knife was used to scrape a very thin layer of bark from a $10 \mathrm{~cm} \mathrm{sec-}$ tion of trunk. The trunks of 2-year-old HLB-affected citrus trees were then wrapped with a $24 \times 12 \mathrm{~cm}$ sponge. The nano-formulations were then applied to the sponges in a volume of $500 \mathrm{ml}$ in each plant. Each experiment was repeated twice for the in vitro bioassays. Two leaves for the pharmacokinetic analysis were taken from each treated plant on days $0,2,4,6,8,10$, and 15 after the initial treatment.

Pharmacokinetic parameters of the nano-emulsions were determined using bioassay methods. The old leaves in the treated citrus were collected. The surfaces of the collected leaves were rinsed three times with sterile water and then washed by spraying the leaves with $1 \%$ Aquet solution and rubbing them gently with gloved hands. After the leaves were rinsed, excess water was shaken off, and then the leaves were placed on paper towels to air dry. Subsequently, $0.5 \mathrm{~g}$ of leaf tissue was cut and placed into an extraction bag (Bioreba, Switzerland) with $1 \mathrm{ml}$ sterile water. The leaves were homogenized by rotating the homogenizing head of a Homex homogenizer (Bioreba, Switzerland) on top of the sample bag until the leaf tissue was pulverized. The leaf homogenate was then transferred into $1.5 \mathrm{ml}$ sterile tubes and centrifuged for $5 \mathrm{~min}$ at $13,000 \mathrm{rpm}$. The supernatant was collected and stored at $-20^{\circ} \mathrm{C}$ until further analysis.

The ampicillin-sensitive bacterium Bacillus subtilis was spread on plates containing LB agar medium. Fifty microliters of leaf extracts

Table 1. Nano-emulsion constituent proportions $\%(w / w)$ using the spontaneous emulsion process before and after solvent evaporation

\begin{tabular}{lcc}
\hline Compound & $\begin{array}{c}\text { Before evaporation } \\
(\% \text { w/w })\end{array}$ & $\begin{array}{c}\text { After evaporation } \\
(\% \text { w/w })\end{array}$ \\
\hline Lipophilic surfactant & 0.13 & 0.14 \\
Hydrophilic surfactant & 0.26 & 0.28 \\
Oil & 0.91 & 1 \\
Water & 89.9 & 98.58 \\
Water-miscible solvent & 8.8 & 0 \\
\hline
\end{tabular}


were applied as $4 \mathrm{~mm}$ spots onto the center of the plate. The dishes were then incubated at $28^{\circ} \mathrm{C}$ for $24 \mathrm{~h}$. Following this incubation period, the inhibitory zone of bacterial growth was measured. The zone diameter was indicative of the amount of ampicillin in the leaf extract during the experimental period. The Amp content was calculated using the following formula (Supplementary Fig. S1):

$$
\log \mathrm{y}=5.12 \mathrm{x}\left(\mathrm{R}^{2}=0.99 \text { by least squares method }\right)
$$

where $\mathrm{x}$ is the Amp content in ng and $\mathrm{y}$ is the diameter of inhibition zone in $\mathrm{cm}$. Pharmacokinetic parameters were calculated using PK functions for Microsoft Excel software (Allergan, CA), including peak of maximum concentration $\left(\mathrm{C}_{\max }\right)$, time of peak concentration $\left(\mathrm{t}_{\max }\right)$, area under moment curve concentration time profile curve until last observation $\left(\mathrm{AUC}_{0 \rightarrow 15 \mathrm{~d}}\right)$, and area under moment curve computed to the last observation $\left(\mathrm{AUMC}_{0 \rightarrow 15 \mathrm{~d}}\right)$. Mean residence time $\left(\mathrm{MRT}_{0 \rightarrow 15 \mathrm{~d}}\right)$ is the average time that the nanoparticle remained in a compartment or system and was computed as MRT $0 \rightarrow 15 \mathrm{~d}=\mathrm{AUMC}_{0 \rightarrow 15 \mathrm{~d}} / \mathrm{AUC}_{0 \rightarrow 15 \mathrm{~d}}$, and relative bioavailability $(\mathrm{RBA} \%)=\mathrm{AUC}_{0 \rightarrow 15} \mathrm{~d}$ (Nano-Cre-Amp or Nano-Soy-Amp)/AUC $\mathrm{A}_{0 \rightarrow 15 \mathrm{~d}}$ (Amp solution). The data were analyzed by Duncan's multiple range test using SAS software package.

Activity of the five antimicrobial nano-formulations against Las. Five antimicrobials, including validoxylamine (VA), combination of actidione (Act) and validoxylamine (Act+VA), sulfadimethoxine sodium (SDX), zhongshengmycin (ZS), and ampicillin (Amp), were prepared into a nano-formulation for an activity test against Las in planta using the optimized nano-emulsion Nano-Cre. The nano-emulsion in water containing $0.1 \%$ Brij 35 was dissolved into $1,000 \mathrm{mg} / \mathrm{liter}$ $\mathrm{VA}$, Act+VA (Act at $50 \mathrm{mg} / \mathrm{liter}$ and VA at $1,000 \mathrm{mg} / \mathrm{liter}$ ), $1,000 \mathrm{mg} / \mathrm{liter} \mathrm{SDX}, 1,000 \mathrm{mg} / \mathrm{liter} \mathrm{ZS}$, or 1,000 mg/liter Amp solution at a ratio of $1: 50 \mathrm{~g} / \mathrm{ml}(\mathrm{w} / \mathrm{v})$ to yield five antimicrobial nanoformulations, respectively. Tap water (CK) was used as a blank control. To evaluate the nano-emulsion capacity, the five antimicrobials (VA, Act+VA, SDX, ZS, and Amp) were prepared in a water solution at the same concentration as their contrasts, respectively. All formulations were applied in the citrus bark with six replicates. The antimicrobial nano-formulations and their water solutions were then applied to the sponges in a volume of $500 \mathrm{ml}$, respectively. Each experiment was repeated twice to test their activities against Las using 10 HLB-affected plants. Five leaves from each treated plant were taken for a qPCR test on days 0, 60, 120, and 180 after the initial treatments. The resulting $\mathrm{Ct}$ values were converted to the estimated bacterial titers using the grand universal regression equation $\mathrm{y}=13.82-0.2866 \mathrm{x}$, where $\mathrm{y}$ is the estimated Log concentration of template and $\mathrm{x}$ is the $\mathrm{Ct}$ values from $\mathrm{qPCR}$, as previously

Table 2. Effect of different oil, surfactant combination, and organic solvent on droplet size $( \pm$ SE) and polydispersity index (PDI) $( \pm$ SE) of nano-emulsion prepared by a spontaneous emulsification method ${ }^{\mathrm{z}}$

\begin{tabular}{lcc}
\hline Compositions & Droplet size $(\mathbf{n m})$ & PDI \\
\hline Oil type & & \\
Soybean oil & $863.18 \pm 73.97 \mathrm{c}$ & $0.43 \pm 0.04 \mathrm{a}$ \\
Cremophor EL & $280.18 \pm 30.22 \mathrm{~d}$ & $0.34 \pm 0.02 \mathrm{~b}$ \\
Carvacrol & $1,104.33 \pm 123.35 \mathrm{~b}$ & $0.50 \pm 0.02 \mathrm{a}$ \\
P-cymene & $1,353.06 \pm 141.60 \mathrm{a}$ & $0.48 \pm 0.03 \mathrm{a}$ \\
Surfactant combination & & \\
Span 85/Tween 20 & $1,068.17 \pm 145.57 \mathrm{a}$ & $0.40 \pm 0.04 \mathrm{~b}$ \\
Span 80/Tween 80 & $788.35 \pm 116.14 \mathrm{~d}$ & $0.44 \pm 0.03 \mathrm{~b}$ \\
Span 80/Tween 20 & $911.52 \pm 105.45 \mathrm{~b}$ & $0.41 \pm 0.03 \mathrm{~b}$ \\
Span 85/Tween 80 & $832.71 \pm 76.19 \mathrm{c}$ & $0.50 \pm 0.03 \mathrm{a}$ \\
Organic solvent & & \\
Acetone & $344.47 \pm 44.47 \mathrm{e}$ & $0.34 \pm 0.03 \mathrm{c}$ \\
Ethanol & $459.98 \pm 39.64 \mathrm{~d}$ & $0.39 \pm 0.02 \mathrm{~b}$ \\
2-Butanone & $825.25 \pm 91.82 \mathrm{c}$ & $0.43 \pm 0.04 \mathrm{~b}$ \\
Methyl acetate & $1,730.02 \pm 175.74 \mathrm{a}$ & $0.53 \pm 0.04 \mathrm{a}$ \\
Ethyl acetate & $1,141.22 \pm 112.32 \mathrm{~b}$ & $0.50 \pm 0.03 \mathrm{a}$ \\
\hline
\end{tabular}

${ }^{z}$ All data were analyzed by Duncan's multiple range test using SAS software package. Different letters represent significant difference at a level of $P \leq$ 0.05 . described ( $\mathrm{Li}$ et al. 2008). The data were analyzed by Duncan's multiple range test using SAS software package.

Genomic DNA extraction and qPCR analysis. Each leaf was rinsed three times with sterile water. Midribs were separated from the leaf samples and cut into 1.0 to $2.0 \mathrm{~mm}$ pieces. DNA was extracted from $0.1 \mathrm{~g}$ (fresh weight) of leaf midrib tissue using a DNeasy Plant Mini Kit (Qiagen, Valencia, CA) according to the manufacturer's protocol. qPCR was performed with primers and probes (HLBas, HLBr, and HLBp) for $\mathrm{Ca}$. L. asiaticus (Li et al. 2006) using the ABI 7500 Fast Real-Time PCR System (Applied Biosystems, Foster City, CA) in a $20 \mu \mathrm{l}$ reaction volume consisting of the following reagents: $300 \mathrm{nM}$ (each) target primer (HLBas and HLBr), $150 \mathrm{nM}$ target probe (HLBp), and $1 \times$ TaqMan qPCR Mix (Applied Biosystems). The amplification protocol was as follows: $95^{\circ} \mathrm{C}$ for $20 \mathrm{~s}$ followed by 40 cycles at $95^{\circ} \mathrm{C}$ for $3 \mathrm{~s}$ and $60^{\circ} \mathrm{C}$ for $30 \mathrm{~s}$. All reactions were performed in triplicate and each reaction contained one negative (DNA from healthy plant) and one positive (DNA from $\mathrm{Ca}$. L. asiaticus-infected plant) control. The positive control was the same for all the runs and was checked to ensure that the $\mathrm{Ct}$ remained constant. Data were analyzed using the ABI 7500 Fast Real-Time PCR System with SDS software.

\section{Results}

Optimization and characterization of oil-in-water nanoemulsions. The effects of oil, surfactant combination, and organic solvent on the droplet size and PDI of the nano-emulsion were determined using the Zetasizer NanoZS apparatus. Variance analysis showed that there were significant effects of oil $(P=0.0001, P=$ $0.0062)$, surfactant combination $(P=0.0001, P=0.0001)$, and organic solvent $(P=0.0001, P=0.0001)$ and their interaction $(P=$ $0.0001, P=0.0001)$ on the droplet size and PDI of the nanoemulsion, respectively. For oil optimization, the mean size of the nano-emulsion formed by Cremophor EL was significantly smaller than that mixed by soybean oil, carvacrol, and P-cymene ( $P \leq$ 0.05 ) (Table 2). The PDIs of the nano-emulsions prepared with Cremophor EL were also significantly smaller than those prepared with soybean oil, carvacrol, or P-cymene $(P \leq 0.05)$ (Table 2$)$.

The mean size of the nano-emulsion droplets that were further stabilized by a combination of two surfactants showed that the surfactant combination of Span 80/Tween 80 significantly reduced the droplet size (Table 2). However, no significant difference in the PDI was observed for the combinations of Span 80/Tween 20, Span $80 /$ Tween 20 , or Span 85/Tween 80 , with the exception of Span 85/Tween 80 (Table 2).

Solvent optimization results indicated that the mean sizes and the PDI of nano-emulsions obtained with acetone were significantly smaller than those that were produced using ethanol, 2-butanone, methyl acetate, and ethyl acetate $(P \leq 0.05)$ (Table 2$)$. The optimized nano-emulsion that was composed of Cremophor EL, the surfactant combination of Span 80/Tween 80, and the solvent acetone had small droplet sizes $(17.33 \pm 0.52 \mathrm{~nm})$ and low turbidity (Supplementary Table S1 and Fig. 1).

Pharmacokinetic analysis of nano-formulations on citrus. In vitro pharmacokinetic analysis showed that the Nano-Cre-Amp formulation promoted significantly more uptake of Amp than the NanoSoy-Amp formulation and Amp water solution (Amp) (Fig. 2) and no Amp was detected in the blank control. The results (Table 3) further indicated that the $t_{\max }$ of Nano-Cre-Amp was 2 days, which was much shorter than that of Nano-Soy-Amp (4 days) and Amp (6 days). The maximum concentration $\left(\mathrm{C}_{\max }\right)$ of ampicillin in Nano-Cre-Amp was 1.35- and 1.27-fold higher than that observed in Nano-Soy-Amp and Amp, respectively. Similarly, the area under moment curve $\left(\mathrm{AUC}_{0 \rightarrow 15 \mathrm{~d}}\right.$ ) of Nano-Cre-Amp was 2.74- and 3.75-fold greater than that of the Nano-Soy-Amp and Amp, respectively $(P=0.0168)$, whereas there was no significant difference between Nano-SoyAmp and Amp. Moreover, the mean residence time $\left(\mathrm{MRT}_{0 \rightarrow 15 \mathrm{~d}}\right)$ of Nano-Cre-Amp was longer than that for Nano-Soy-Amp and Amp. In addition, the relative bioavailability of Nano-Cre-Amp was $267.3 \% \pm 44.1 \%$, which was significant higher than that of the Nano-Soy-Amp (Table 3) $(P=0.0349)$. Therefore, the Nano-Cre was an ideal nano-emulsion for enhancing delivery efficacy. 
Characterization and activity of five antimicrobial nanoformulations against Las. Each of the antimicrobials (VA, Act+ VA, SDX, ZS, or Amp) and the tap water (CK) was loaded to the optimized nano-emulsion of Nano-Cre. The water solutions of the above antimicrobials were used as controls. The results showed that
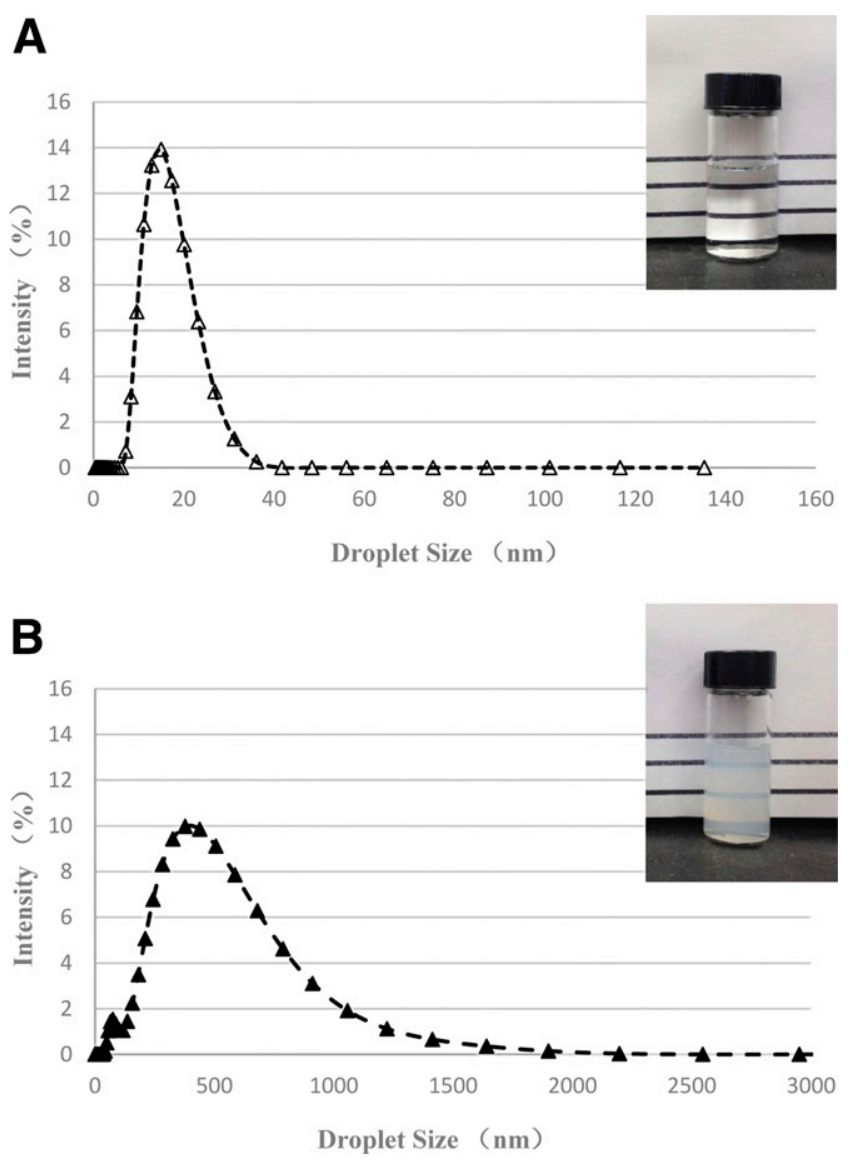

Fig. 1. Particle size distributions of nano-emulsions obtained with Cremophor EL (Nano-Cre) and soybean oil (Nano-Soy), with the other components being the same, including Span 80/Tween 80, acetone, and tap water. A, Particle size distributions of nano-emulsions (Nano-Cre). B, Particle size distributions of nanoemulsions (Nano-Soy).
Nano-Cre significantly reduced the droplet size of the antimicrobial formulations and changed their physicochemical characteristics (Table 4). In addition, ZS prepared in the nano-emulsion had the largest droplet compared with VA, Act+VA, SDX, or Amp (Table 4).

When the nano-antimicrobial formulations were applied to the bark of HLB-affected citrus trees in the greenhouse, VA, Act+VA, and SDX significantly reduced the Las titers in HLB-affected citrus at 180 days after the initial treatment (Fig. 3), while their water solutions had no significant effects on reduction of Las titers in HLBaffected citrus (Fig. 3). Amp exhibited significant therapeutic ability against Las in both the nano-formulation and water solution (Fig. 3), while the ZS nano-emulsion had no significant effect on the therapeutic capacity against Las (Fig. 3).

\section{Discussion}

In our previous study, we developed a W/O nano-emulsion to facilitate antimicrobials penetrating into citrus phloem through the leaf cuticle against Las. The results indicated that there were no Las detection in HLB-affected citrus treated with a W/O nano-emulsion coupled with ampicillin 6 months after the initial treatment (Yang et al. 2015). In this paper, based on the fact that citrus bark is hydrophilic, an O/W nano-emulsion was developed to enhance the delivery efficacy of antimicrobials into citrus phloem through citrus bark. Our results demonstrated that when the $\mathrm{O} / \mathrm{W}$ nano-emulsion coupled with ampicillin was applied to HLB-affected citrus through bark application, very low Las titers were detected in the citrus 2 months after the initial treatment, which is a more effective treatment than that presented in our previous study. Therefore, this study provides an optimized $\mathrm{O} / \mathrm{W}$ nano-emulsion (Nano-Cre) to enhance the delivery and activity of antimicrobials against Las.

Ampicillin (Amp) is an ideal target compound for pharmacokinetic analysis of the nano-emulsion in citrus because it is easily taken up by the plant (Zhang et al. 2013). The results presented here indicate that an optimized nano-formulation of Nano-Cre-Amp greatly improved the bioavailability, absorption rate, and stability of ampicillin (Table 3). This nano-emulsion effectively delivered antimicrobials to citrus phloem and enhanced their efficacies against Las. VA, Act+VA, and SDX prepared as nano-emulsions significantly reduced Las titers in HLB-affected citrus (Fig. 3). However, the ZS nanoemulsion did not have a significant effect against Las (Fig. 3). All of these antimicrobials have been previously shown to be effective or partly effective against Las in a graft-based assay (Zhang et al. 2014).

Amp is one of the most effective antibiotics against Las (Zhang et al. 2013, 2014). Indeed, we found that Amp prepared as a

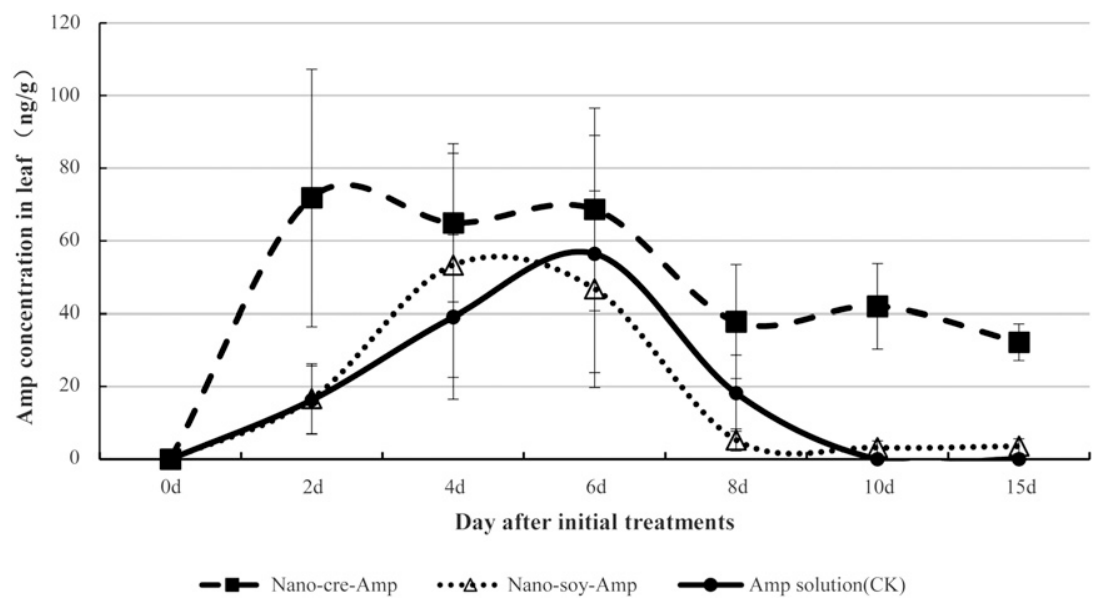

Fig. 2. Amp concentration in HLB-affected citrus leaves after application of Nano-Amp formulations to tree bark. The error bars indicate that standard error. Nano-Cre-Amp: Ampicillin at a final concentration of 3,000 mg/liter dissolved in the prepared nano-emulsion obtained with Cremophor EL, Span 80/Tween 80, acetone, and tap water containing $0.1 \%$ Brij 35. Nano-Soy-Amp: Ampicillin at final concentration of 3,000 mg/liter dissolved in the prepared nano-emulsion obtained with soybean oil, Span $80 / T$ ween 80, acetone, and tap water containing $0.1 \%$ Brij 35 . Amp solution (Amp): Ampicillin was directly dissolved in water containing $0.1 \%$ Brij 35 to a final concentration of 3,000 $\mathrm{mg} /$ liter. 
nano-emulsion or water solution could significantly reduce Las titers in the HLB-affected citrus. The translocation of antimicrobials in planta is dependent on the chemical structure and other properties, such as inorganic ions and molecular size (Bromilow and Chamberlain 1995). In this study, the optimized Nano-Cre altered the characteristics of the antimicrobial formulation and significantly reduced the droplet size of the emulsion (Table 4). Therefore, the delivery efficacy of VA, Act+VA, and SDX into citrus phloem may have been enhanced through the aid of the nano-emulsion. The ZS nano-emulsion had a larger droplet size than the other antimicrobial (VA, Act+VA, and SDX) nano-formulations (Table 4). Therefore, the larger droplet size of the ZS nano-emulsion might have affected the translocation of ZS into citrus and reduced its efficacy against Las. VA has been widely used in agriculture to control plant disease (Ishikawa et al. 2005) and its optimized nano-emulsion displayed a remarkable reduction of Las titers (Fig. 3). Since the EPA has classified VA as Toxicity Class IV, which is a nontoxic group that is currently regulated, the VA nanoformulation may have a great potential for HLB control.

Nano-emulsions with a small droplet size are promising drug delivery vehicles in the pharmaceutical and food industries because of their properties to improve drug bioavailability, absorption rates, and stability (Shafiq et al. 2007). A nano-emulsion system with a small droplet size also covers a much larger surface area, which may facilitate compound solubility and increase the drug absorption rate (Tadros et al. 2004). In addition, the small droplet size of nanoemulsions typically enhances resistance to gravitational separation, flocculation, and coalescence (Mason et al. 2006; Tadros et al. 2004). The droplet size of nano-emulsions formulated using the spontaneous emulsification method is often affected by physiochemical characteristics of the oil, surfactant, and organic solvent that are used in the solution (Bouchemal et al. 2004; Miller 1988). Here, the nanoformulation of Nano-Cre-Amp that was prepared from Cremophor EL oil, the surfactant combination Span 80/Tween 80, and acetone as an organic solvent with subsequent addition of the ampicillin solution exhibited a small droplet size of $17.33 \pm 0.52 \mathrm{~nm}$. Cremophor EL has a higher viscosity compared with soybean oil, carvacrol, and P-cymene. Based on its high viscosity, Cremophor EL formed a nano-emulsion with the smallest droplet size (Table 3). Our results are consistent with findings by Pal's group who demonstrated that the droplet size of emulsions decreased when the oil viscosity increased (Pal 1998). Cremophor EL has been widely used as a method to prepare nano-emulsions in the pharmaceutical industry (Sparreboom et al. 1996). Our study demonstrated that Cremophor EL can produce a droplet that is small enough to enhance the delivery efficacy of the antimicrobials for citrus HLB control.

Various organic solutions can also affect the droplet size of nanoemulsions (Song et al. 2006). The emulsion droplet size with acetone as the solvent was significantly smaller than that with other solvents tested (ethanol, 2-butanone, methyl acetate, or ethyl acetate) due to high miscibility of acetone in water (Table 3 ). In nano-emulsion systems, a small droplet size is ascribed as a lower interfacial tension between the aqueous and organic phases that results from the water soluble nature of the organic solvent (Bouchemal et al. 2004). Although ethanol is also water miscible, the droplet size of the emulsions obtained from it was significantly larger than that of acetone. This larger droplet size may be due to the fact that ethanol can undergo a secondary reaction between alcohol compounds $(-\mathrm{OH})$ and unknown monomers used for nano-emulsion synthesis during interfacial polycondensation. To further justify the solvent choice for nano-emulsion production, the solvent flash point $(\mathrm{FP})$ should also be considered. Unlike acetone $\left(\mathrm{FP}=-18^{\circ} \mathrm{C}\right)$, ethanol $\left(\mathrm{FP}=14^{\circ} \mathrm{C}\right)$, 2-butanone $\left(\mathrm{FP}=-9^{\circ} \mathrm{C}\right)$, methyl acetate $\left(\mathrm{FP}=-10^{\circ} \mathrm{C}\right)$, and ethyl acetate $\left(\mathrm{FP}=-4^{\circ} \mathrm{C}\right)$ have a higher risk of auto inflammation upon heating, which would make acetone the safer organic solvent for use in a nano-emulsion preparation.

The nano-emulsions were stabilized through a combination of two surfactants, Span 80 and Tween 80 . The droplet size can also be related to the hydrophilic-lipophilic balance value of the nano system, with which the higher values present a smaller droplet (Bouchemal et al. 2004). In this study, the hydrophilic-lipophilic balance value of these surfactant combinations (Span 80/Tween $80=11.4$, Span $85 /$ Tween $20=11.3$, Span $85 /$ Tween $80=10.6$, Span $80 /$ Tween $20=12.1$ ) showed little variation since the nano-emulsion droplet size did not fluctuate widely. The droplet size of the nano-emulsions

Table 3. Relative bioavailability and pharmacokinetic parameters $( \pm \mathrm{SE})$ of two prepared nano-formulations and Amp solution when applied to HLB-affected citrus $^{\mathrm{t}}$

\begin{tabular}{lcccccc}
\hline Formulation & $\mathbf{t}_{\mathbf{m a x}}{ }^{\mathbf{u}}(\mathbf{d})$ & $\mathbf{C}_{\mathbf{m a x}} \mathbf{v}(\mathbf{n g} / \mathbf{g})$ & $\mathbf{A U C}_{\mathbf{0} \rightarrow \mathbf{1 5 d}} \mathbf{w}(\mathbf{n g ~ h} / \mathbf{m l})$ & $\mathbf{A U M C}_{\mathbf{0} \rightarrow \mathbf{1 5 d}} \mathbf{x}(\mathbf{n g} \mathbf{h} / \mathbf{m l})$ & $\mathbf{M R T}_{\mathbf{0} \rightarrow \mathbf{1 5 d}}^{\mathbf{y}}(\mathbf{d})$ & $\mathbf{R e l . ~ B A}^{\mathbf{z}}(\boldsymbol{\%})$ \\
\hline Nano-Cre-Amp & 2 & $71.9 \pm 35.4 \mathrm{a}$ & $695.1 \pm 114.6 \mathrm{a}$ & $51,917.9 \pm 15,827.3 \mathrm{a}$ & $71.1 \pm 16.0 \mathrm{a}$ & $267.3 \pm 44.1 \mathrm{a}$ \\
Nano-Soy-Amp & 4 & $53.3 \pm 30.8 \mathrm{a}$ & $264.3 \pm 75.6 \mathrm{~b}$ & $16,732.3 \pm 6,466.8 \mathrm{~b}$ & $59.2 \pm 7.5 \mathrm{a}$ & $101.6 \pm 29.1 \mathrm{~b}$ \\
Amp solution (Amp) & 6 & $56.4 \pm 32.6 \mathrm{a}$ & $260.1 \pm 51.5 \mathrm{~b}$ & $12,256.2 \pm 3,580.6 \mathrm{~b}$ & $45.6 \pm 5.5 \mathrm{a}$ & - \\
\hline
\end{tabular}

t All data were analyzed by Duncan's multiple range test using SAS software package. Different letters represent significant difference at a level of $P \leq 0.05$.

u Time of peak concentration.

${ }^{v}$ Maximum concentration.

w Area under moment curve concentration time profile curve until last observation.

$\times$ Area under moment curve computed to the last observation.

y Mean residence time.

z Relative bioavailability.

Table 4. Comparison of physiochemical characteristics $( \pm \mathrm{SE})$ of various antibiotics coupled with and without nano-emulsion $(\mathrm{Cre}-\mathrm{Nano})^{\mathrm{z}}$

\begin{tabular}{|c|c|c|c|c|c|c|c|}
\hline Chemical compounds & Formulation type & Droplet size (nm) & PDI & $\mathbf{Z P}(\mathbf{m V})$ & $\operatorname{Mob}(\mu \mathrm{m} / \mathrm{Vs})$ & Cond $(\mathrm{mS} / \mathrm{cm})$ & pH \\
\hline \multirow[t]{2}{*}{ VA } & Nano-formulation & $163.2 \pm 11.6 \mathrm{~b}$ & $0.6 \pm 0.03 \mathrm{a}$ & $-1.5 \pm 0.06 \mathrm{a}$ & $-0.12 \pm 0 \mathrm{a}$ & $0.26 \pm 0.02 b$ & $4.62 \pm 0.01 \mathrm{a}$ \\
\hline & Water solution & $1,994.3 \pm 116.5 \mathrm{a}$ & $0.5 \pm 0.05 \mathrm{a}$ & $-11.2 \pm 0.23 b$ & $-0.88 \pm 0.02 b$ & $1.01 \pm 0.03 \mathrm{a}$ & $3.95 \pm 0.02 b$ \\
\hline \multirow[t]{2}{*}{ Act+VA } & Nano-formulation & $166.9 \pm 16.8 \mathrm{~b}$ & $0.7 \pm 0.09 \mathrm{a}$ & $-3.6 \pm 0.09 \mathrm{a}$ & $-0.28 \pm 0.01 \mathrm{a}$ & $0.52 \pm 0.01 b$ & $4.45 \pm 0.08 \mathrm{~b}$ \\
\hline & Water solution & $1,950.3 \pm 55.2 \mathrm{a}$ & $0.6 \pm 0.06 \mathrm{a}$ & $-10.0 \pm 0.52 \mathrm{~b}$ & $-0.78 \pm 0.04 b$ & $1.04 \pm 0.03 \mathrm{a}$ & $4.75 \pm 0.03 \mathrm{a}$ \\
\hline \multirow[t]{2}{*}{ SDX } & Nano-formulation & $18.6 \pm 0.8 \mathrm{~b}$ & $0.3 \pm 0.02 b$ & $-1.2 \pm 0.23 \mathrm{a}$ & $-0.09 \pm 0.02 \mathrm{a}$ & $0.15 \pm 0.01 b$ & $7.49 \pm 0.01 \mathrm{a}$ \\
\hline & Water solution & $326.8 \pm 37.8 \mathrm{a}$ & $0.7 \pm 0.04 \mathrm{a}$ & $-6.0 \pm 1.34 b$ & $-0.47 \pm 0.11 \mathrm{~b}$ & $0.18 \pm 0 \mathrm{a}$ & $6.85 \pm 0.02 b$ \\
\hline \multirow[t]{2}{*}{$\mathrm{ZS}$} & Nano-formulation & $783.8 \pm 44.1 \mathrm{~b}$ & $0.9 \pm 0.07 \mathrm{a}$ & $-4.0 \pm 0.05 a$ & $-0.31 \pm 0 \mathrm{a}$ & $0.09 \pm 0 \mathrm{~b}$ & $5.47 \pm 0.01 \mathrm{a}$ \\
\hline & Water solution & $953.5 \pm 19.1 \mathrm{a}$ & $0.4 \pm 0.01 b$ & $-4.8 \pm 0.25 b$ & $-0.37 \pm 0.02 b$ & $0.13 \pm 0 \mathrm{a}$ & $4.29 \pm 0.05 b$ \\
\hline \multirow[t]{2}{*}{ Amp } & Nano-formulation & $29.9 \pm 0.1 \mathrm{~b}$ & $0.7 \pm 0.01 \mathrm{a}$ & $-2.7 \pm 0.4 \mathrm{~b}$ & $-0.21 \pm 0.03 b$ & $0.1 \pm 0 \mathrm{a}$ & $4.96 \pm 0.05 \mathrm{a}$ \\
\hline & Water solution & $83.4 \pm 1.7 \mathrm{a}$ & $0.6 \pm 0.06 \mathrm{a}$ & $-0.3 \pm 0.34 \mathrm{a}$ & $-0.03 \pm 0.03 \mathrm{a}$ & $0.1 \pm 0 \mathrm{a}$ & $4.23 \pm 0.01 \mathrm{~b}$ \\
\hline \multirow[t]{2}{*}{ CK } & Nano-formulation & $80.9 \pm 0.4 b$ & $0.4 \pm 0.03 b$ & $-31.6 \pm 0.49 b$ & $-2.47 \pm 0.04 b$ & $0.03 \pm 0 \mathrm{a}$ & $5.21 \pm 0.08 \mathrm{a}$ \\
\hline & Water solution & $108.2 \pm 2.1 \mathrm{a}$ & $1 \pm 0 \mathrm{a}$ & $-15.0 \pm 4.89 \mathrm{a}$ & $-1.18 \pm 0.39 a$ & $0.03 \pm 0 \mathrm{a}$ & $5.28 \pm 0.01 \mathrm{a}$ \\
\hline
\end{tabular}

${ }^{\mathrm{z}}$ All data were analyzed by Duncan's multiple range test using SAS software package. Different letters represent significant difference at a level of $P \leq 0.05$. 
prepared by Span 80/Tween 80 was smaller than that prepared with the other three surfactant combinations (Table 3). Therefore, Span 80/Tween 80 might be the best choice for preparing superior nanoemulsions.

The materials that were used to prepare the nano-emulsions in this study, including Cremophor EL, Span 80, Tween 80, and acetone, are rather inexpensive and their emulsions are suitable for bark application, which could reduce the amount of chemicals used in the open environment and may reduce or eliminate the potentially negative effect of the chemicals on humans and nontarget bacteria. Although acetone can be harmful to the environment, it evaporated during the preparation process.
A

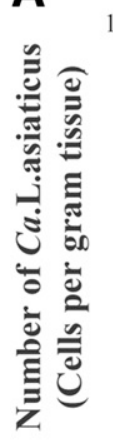

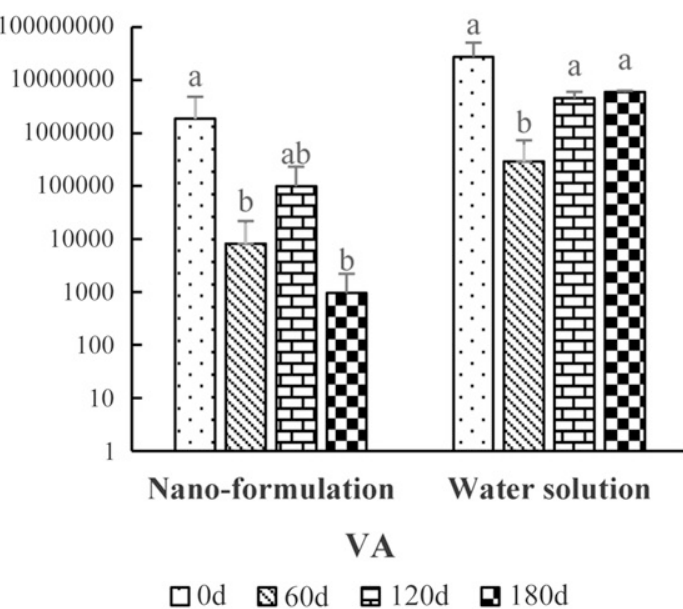

口0d $\triangle 60 \mathrm{~d} \square 120 \mathrm{~d} \quad \mathbf{9} 180 \mathrm{~d}$
B

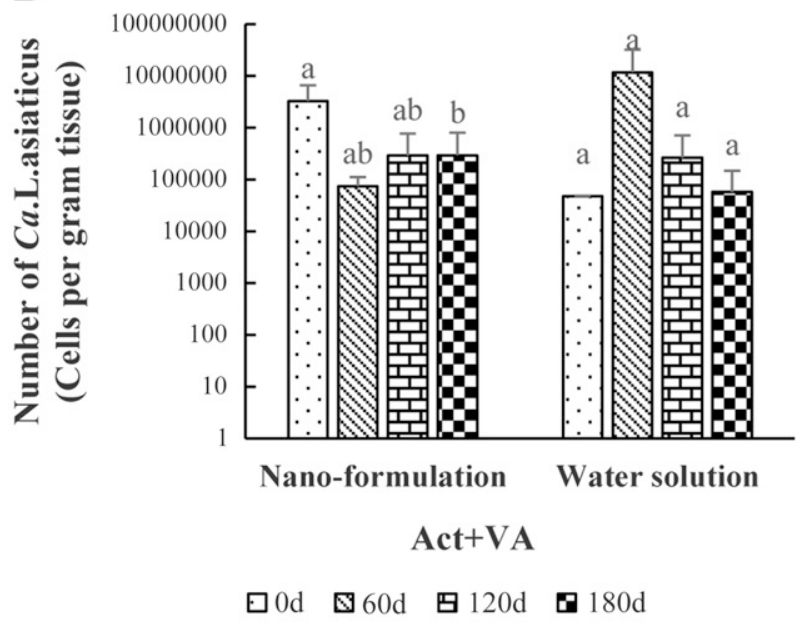

D

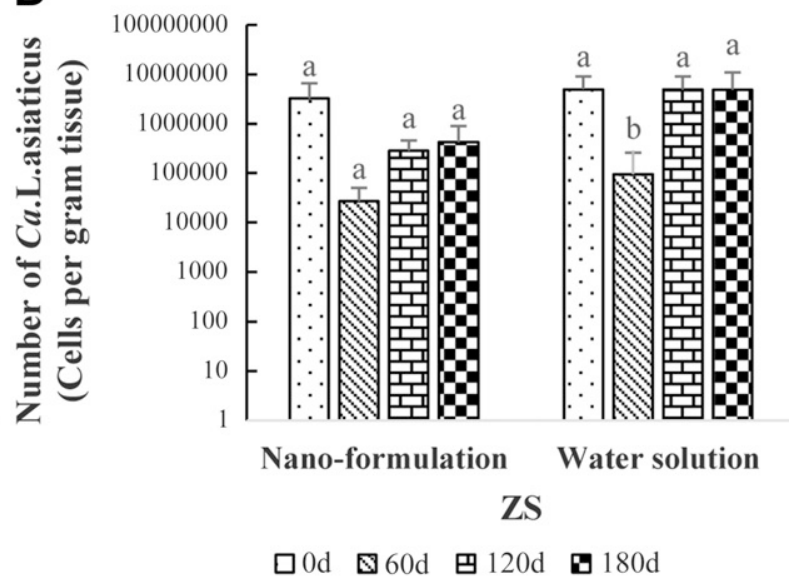

$\mathbf{F}$

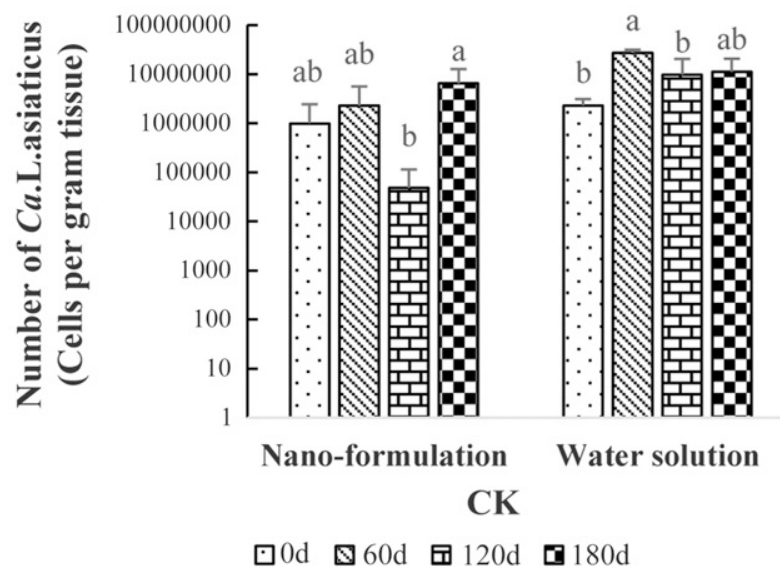

Fig. 3. Comparison of effect of various antibiotics coupled with and without nano-emulsion (Cre-Nano) on Las titer. The error bars indicate that standard error. A, Comparison of effect of validoxylamine A (VA, 1,000 mg/liter) coupled with and without Cre-Nano on Las titer. B, Comparison of effect of combination of actidione (Act, $50 \mathrm{mg} /$ liter) and VA (1,000 $\mathrm{mg} /$ liter) with and without Cre-Nano on Las titer. C, Comparison of effect of sulfadimethoxine sodium (SDX, 1,000 mg/liter) with and without Cre-Nano on Las titer. D, Comparison of effect of zhongshengmycin (ZS, 1,000 mg/liter) with and without Cre-Nano on Las titer. E, Comparison of effect of ampicillin sodium (Amp, 1,000 mg/liter) with and without Cre-Nano on Las titer. F, Comparison of effect of tap water (CK) with and without Cre-Nano on Las titer. 
In summary, this study provides an optimized and nano-emulsionbased delivery system for antimicrobial compounds through bark application in combating citrus HLB. The delivery system was validated to have a potential use for increasing the therapeutic capacity of antimicrobials against Las. This research also provides useful information for designing $\mathrm{O} / \mathrm{W}$ nano-emulsions for small droplets as a delivery vehicle for various pesticides. These nano-emulsions produced using the spontaneous emulsification method may represent a cost-efficient and eco-friendly method for controlling plant disease.

\section{Acknowledgments}

We greatly appreciate Bioscience Editing Solutions for critically reading this paper and providing helpful suggestions. Financial support was provided by U.S. Citrus Research and Development Foundation (project CRDF\#584) and Guangxi Natural Science Foundation (project 2013GXNSFFA118002).

\section{Literature Cited}

Anton, N., Benoit, J.-P., and Saulnier, P. 2008. Design and production of nanoparticles formulated from nano-emulsion templates-a review. J. Control. Release 128:185-199.

Bouchemal, K., Briançon, S., Perrier, E., and Fessi, H. 2004. Nano-emulsion formulation using spontaneous emulsification: solvent, oil and surfactant optimisation. Int. J. Pharm. 280:241-251.

Bové, J. M. 2006. Huanglongbing: A destructive, newly-emerging, century-old disease of citrus. J. Plant Pathol. 88:7-37.

Bové, J. M., and Ayres, A. J. 2007. Etiology of three recent diseases of citrus in Sao Paulo State: sudden death, variegated chlorosis and huanglongbing. IUBMB Life 59:346-354

Bromilow, R. H., and Chamberlain, K. 1995. Principles governing uptake and transport of chemicals. Pages 37-68 in: Plant Contamination: Modeling and Simulation of Organic Chemical Processes: S. Trapp and J. C. McFarlane, eds. Lewis Publishers, New York.

Chang, Y., and McClements, D. J. 2014. Optimization of orange oil nanoemulsion formation by isothermal low-energy methods: Influence of the oil phase, surfactant, and temperature. J. Agric. Food Chem. 62:2306-2312.

Chen, M., Jensen, S. P., Hill, M. R., Moore, G., He, Z., and Sumerlin, B. S. 2015. Synthesis of amphiphilic polysuccinimide star copolymrs for responsive delivery in plants. Chem. Commun. (Camb.) 51:9694-9697.

da Graça, J., and Korsten, L. 2004. Citrus huanglongbing: Review, present status and future strategies. Pages 229-245 in: Diseases of Fruits and Vegetables. S. A. M. H. Naqvi, ed. Kluwer Academic Publishers, Dordrecht, The Netherlands.

Date, A. A., Desai, N., Dixit, R., and Nagarsenker, M. 2010. Self-nanoemulsifying drug delivery systems: formulation insights, applications and advances. Nanomedicine-UK 5:1595-1616.

Gottwald, T. R. 2010. Current epidemiological understanding of citrus Huanglongbing. Annu. Rev. Phytopathol. 48:119-139.

Gulotta, A., Saberi, A. H., Nicoli, M. C., and McClements, D. J. 2014. Nanoemulsion-based delivery systems for polyunsaturated $(\omega-3)$ oils: Formation using a spontaneous emulsification method. J. Agric. Food Chem. 62:1720-1725.

Hill, M. R., MacKrell, E. J., Forsthoefel, C. P., Jensen, S. P., Chen, M., Moore, G. A., He, Z. L., and Sumerlin, B. S. 2015. Biodegradable and pH-responsive nanoparticles designed for site-specific delivery in agriculture. Biomacromolecules 16:1276-1282.

Hodges, A., and Spreen, T. 2012. Economic impacts of citrus greening (HLB) in Florida, 2006/07 to 2010/2011. Document FE903, Institute of Food and Agricultural Sciences, University of Florida.

Ishikawa, R., Shirouzu, K., Nakashita, H., Lee, H.-Y., Motoyama, T., Yamaguchi, I., Teraoka, T., and Arie, T. 2005. Foliar spray of validamycin A or validoxylamine A controls tomato Fusarium wilt. Phytopathology 95:1209-1216.

Jagoueix, S., Bové, J. M., and Garnier, M. 1994. The phloem-limited bacterium of greening disease of citrus is a member of the alpha subdivision of the Proteobacteria. Int. J. Syst. Bacteriol. 44:379-386.

Kah, M., and Hofmann, T. 2014. Nanopesticide research: current trends and future priorities. Environ. Int. 63:224-235.

Li, W., Hartung, J. S., and Levy, L. 2006. Quantitative real-time PCR for detection and identification of Candidatus Liberibacter species associated with citrus huanglongbing. J. Microbiol. Methods 66:104-115.

Li, W., Li, D., Twieg, E., Hartung, J. S., and Levy, L. 2008. Optimized quantification of unculturable Candidatus Liberibacter spp. in host plants using real-time PCR. Plant Dis. 92:854-861.

Lopes, S. A., and Frare, G. F. 2008. Graft transmission and cultivar reaction of citrus to 'Candidatus Liberibacter americanus'. Plant Dis. 92:21-24.

López-Montilla, J. C., Herrera-Morales, P. E., Pandey, S., and Shah, D. O. 2002. Spontaneous emulsification: mechanisms, physicochemical aspects, modeling, and applications. J Disp Sci Tech. 23:219-268.

Mason, T. G., Wilking, J., Meleson, K., Chang, C., and Graves, S. 2006. Nanoemulsions: formation, structure, and physical properties. J. Phys. Condens. Matter 18:R635.
Miller, C. A. 1988. Spontaneous emulsification produced by diffusion-a review. Colloids Surf. 29:89-102.

Nariani, T. K., Raychaudhuri, S. P., and Viswanath, S. M. 1973. Tolerance to greening disease in certain citrus species. Curr. Sci. 42:513-514.

Neupane, D., Moss, C. B., and van Bruggen, A. H. 2016. Estimating citrus production loss due to citrus huanglongbing in Florida. In: 2016 Annual Meeting, Southern Agricultural Economics Association, 6-9 February 2016, San Antonio, TX.

Ostertag, F., Weiss, J., and McClements, D. J. 2012. Low-energy formation of edible nanoemulsions: Factors influencing droplet size produced by emulsion phase inversion. J. Colloid Interface Sci. 388:95-102.

Pal, R. 1998. A novel method to correlate emulsion viscosity data. Collod Surf. A Physicochem. Eng. Asp. 137:275-286.

Saberi, A. H., Fang, Y., and McClements, D. J. 2013. Fabrication of vitamin Eenriched nanoemulsions: factors affecting particle size using spontaneous emulsification. J. Colloid Interface Sci. 391:95-102.

Sekhon, B. S. 2014. Nanotechnology in agri-food production: an overview. Nanotechnol. Sci. Appl. 7:31-53.

Shafiq, S., Shakeel, F., Talegaonkar, S., Ahmad, F. J., Khar, R. K., and Ali, M. 2007. Development and bioavailability assessment of ramipril nanoemulsion formulation. Eur. J. Pharm. Biopharm. 66:227-243.

Solans, C., Izquierdo, P., Nolla, J., Azemar, N., and Garcia-Celma, M. 2005. Nanoemulsions. Curr. Opin. Collod In. 10:102-110.

Song, K. C., Lee, H. S., Choung, I. Y., Cho, K. I., Ahn, Y., and Choi, E. J. 2006. The effect of type of organic phase solvents on the particle size of poly (d, 1lactide-co-glycolide) nanoparticles. Collod Surf. A. 276:162-167.

Song, S., Liu, X., Jiang, J., Qian, Y., Zhang, N., and Wu, Q. 2009. Stability of triazophos in self-nanoemulsifying pesticide delivery system. Collod Surf. A. 350:57-62.

Spann, T. M., Atwood, R. A., Dewdney, M. M., Ebel, R. C., Ehsani, R., England, G., Futch, S. H., Gaver, T., Hurner, T., and Oswalt, C. 2014. IFAS guidance for huanglongbing (greening) management. Document HS1165, University of Florida IFAS Extension.

Sparreboom, A., van Tellingen, O., Nooijen, W. J., and Beijnen, J. H. 1996. Nonlinear pharmacokinetics of paclitaxel in mice results from the pharmaceutical vehicle Cremophor EL. Cancer Res. 56:2112-2115.

Spreen, T. H., Barber, R., Brown, M. G., Hodges, A. W., Malugen, J. C., Mulkey, W. D., Muraro, R. P., Norberg, R. P., Rahmani, M., and Roka, F. M. 2006. An economic assessment of the future prospects for the Florida Citrus Industry. Presentation to the Special Industry Task Force. Florida Department of Citrus, Lakeland, FL.

Tadros, T., Izquierdo, P., Esquena, J., and Solans, C. 2004. Formation and stability of nano-emulsions. Adv. Colloid Interfac. 108-109:303-318.

Texeira, D. C., Ayres, J., de Barros, A. P., Kitajima, E. W., Tanaka, F. A. O., Danet, L., Jagoueix-Eveillard, S., Saillard, C., and Bové, J. M. 2005. First report of a huanglongbing-like disease of citrus in Sao Paulo State, Brazil and association of a new liberibacter species, 'Candidatus Liberibacter americanus', with the disease. Plant Dis. 89:107.

Vandamme, T. F., and Anton, N. 2010. Low-energy nanoemulsification to design veterinary controlled drug delivery devices. Int. J. Nanomedicine 5: 867.

Wang, L., Dong, J., Chen, J., Eastoe, J., and Li, X. 2009. Design and optimization of a new self-nanoemulsifying drug delivery system. J. Colloid Interface Sci. 330:443-448.

Wang, L., Li, X., Zhang, G., Dong, J., and Eastoe, J. 2007. Oil-in-water nanoemulsions for pesticide formulations. J. Colloid Interface Sci. 314: 230-235.

Yang, C., Powell, C. A., Duan, Y., Shatters, R., and Zhang, M. 2015 Antimicrobial nanoemulsion formulation with improved penetration of foliar spray through citrus leaf cuticles to control citrus huanglongbing. PLoS One 10:e0133826.

Zhang, M., Duan, Y., Zhou, L., Turechek, W. W., Stover, E., and Powell, C. A. 2010. Screening molecules for control of citrus huanglongbing using an optimized regeneration system for 'Candidatus Liberibacter asiaticus'infected periwinkle (Catharanthus roseus) cuttings. Phytopathology 100: 239-245.

Zhang, M., Guo, Y., Powell, C. A., Doud, M. S., Yang, C., and Duan, Y. 2014 Effective antibiotics against 'Candidatus Liberibacter asiaticus' in HLBaffected citrus plants identified via the graft-based evaluation. PLoS One 9: e111032.

Zhang, M., Powell, C. A., Guo, Y., Doud, M. S., and Duan, Y. 2012. A graft-based chemotherapy method for screening effective molecules and rescuing huanglongbing-affected citrus plants. Phytopathology 102:567-574.

Zhang, M., Powell, C. A., Zhou, L., He, Z., Stover, E., and Duan, Y. 2011. Chemical compounds effective against the citrus huanglongbing bacterium 'Candidatus Liberibacter asiaticus' in planta. Phytopathology 101:10971103.

Zhang, M. Q., Powell, C. A., Benyon, L. S., Zhou, H., and Duan, Y. P. 2013. Deciphering the bacterial microbiome of citrus plants in response to 'Candidatus Liberibacter asiaticus'-infection and antibiotic treatments. PLoS One 8:e76331. 